\title{
The Unity of Intellect in Aristotle's De Anima
}

\author{
Hua Wang* \\ School of Philosophy, Beijing Normal University, 19 Xinjiekouwai Street, Beijing, 100875, China \\ *Corresponding Author: Hua Wang, School of Philosophy, Beijing Normal University, 19 Xinjiekouwai \\ Street, Beijing, 100875, China

\begin{abstract}
It is argued in this paper that active intellect and passive intellectof DA3.5 are not two kinds of intellect (God and human intellect), as divine interpretation held, but rather two aspects of human intellect. Analogy to knower, active intellect as contemplating knower exists in its potential, that is, passive intellect. Similarly, passive intellect as knower in potentiality also needs active intellect to actualize its essence. These two aspects serve as indispensable condition in human thinking act, active intellect is like the actor who writes the 'word' actuality on the 'writing tablet', that is, the same between the theoretical knowledge and its object; if above two claims admitted, then the active intellect is not identical to God. Furthermore, the

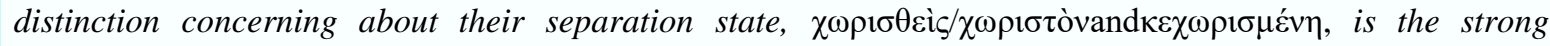
argument to prove it.
\end{abstract}

Keywords: Passive intellect, productive intellect, potential, actuality

\section{ONE INTELLECT OR TWO KINDS OF INTELLECT IN DA3.5?}

De Anima (DA), based on natural philosophy, discusses the principle of all living things which including plants, animals and human beings. The soul is a cause as substance, for substance is the cause of being for all things. Just like nutrition is to plants, perception to animals, and intellect (voṽs) to human beings. A problem raised by Aristotle, it is not clear whether the soul is the actuality of body in the way that a sailor is of a ship ${ }^{2}$. If it is the same way, then it means that intellect exists outside of us. If not, it exists inside of us. Aristotle continues to suppose that "intellect and the capacity for contemplation $(\theta \varepsilon \omega \rho \eta \tau \imath \kappa \tilde{\zeta} \varsigma)$ seems to be a different genus of soul, in the way the everlasting is from

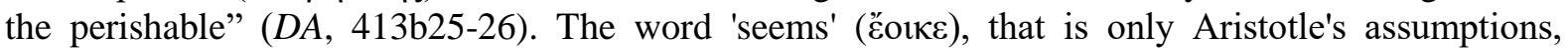
cannot be used as an argument. This problem reached its climax in DA3.5, which Aristotle distinguishes passive intellect and active intellect from the perspective of potential and actuality. Aristotle believes that the former is perishable and the latter is eternal and immortal. It is difficult for us to explain that both perishable and deathless intellect exist in us at the same time. Likewise, it is also difficult to insist that the doctrine of the soul based on natural philosophy is to be transferred to theology or the first philosophy ${ }^{3}$.

\footnotetext{
${ }^{1}$ voũçis one of the most complex and controversial concepts in Aristotle's philosophy, and it runs through Aristotle's entire philosophy. The voũçinMet.L, exists as the unmoved mover, God, which is the highest-level expression; NEis about the virtue of voṽspart in the soul. The text of $D A$ concerning aboutvoũcitself, which is a capacity of human to learn and understand. This capacity explains the connection between us and the world. There are many translations of this word, reason, mind, and voũ s. This article translates voũcinto "intellect" based on medieval traditions.

${ }^{2}$ Cf.DA, $413 \mathrm{a} 9$.

${ }^{3}$ See Victor Caston. Aristotle's two Intellect: A Modest Proposal. Phronesis 44 (1999). This paper has three claims, that are 'there are two kinds of intellect, not one intellect; $D A$, as same asMet. and $N E$, EE, will reach a climax to distinguish the difference between man and God; if above two arguments are true, then God will exercise our intellect through the movement of celestial bodies. The same point of view, see Frede Michael (1995), Burnyeat (2008), Alexander of Aphrodisias(2012). They all the representative people as divine interpretation, see Caleb (2014), Shields(2016). The argument of Professor Caston is very rigorous and persuasive, but I don't fully agree with these claims. This paper argues that the $D A$ is based on natural philosophy, even though human beings have transcendence aspect and activities toward God, but this not means that productive intellect is God. On the contrary, it is precisely because of the active principle of human beings, active intellect, that we can have activities towards to God.
} 
Aristotle's school background will make this issue more complicated, the shadow of Plato is seen in the intellect theory of Aristotle, especially in his early texts and fragments. For example, Aristotle thinks that intellect seems immortal and divine in protrepticus; Proclus suggests that the soul existed before birth and also existed after death for Aristotle ${ }^{4} ; E E$, which is talk about the deathless and eternal. However, whether or not $E E$ was written by Aristotle has not been confirmed, so it is not very reasonable to use this text as an argument. Some commentators consider that these were Aristotle's thoughts when he is young, but after Aristotle discovered the hylomorphism, he abandoned them. So we can only see the shadow of Plato rather than the same standpoint in Aristotle's work.

The active intellect is too mysterious that our reason cannot be explained clearly, even Aristotle himself said "about intellect nothing evident $(D A, 413 \mathrm{~b} 25)$. But we still have to try to solve this problem, it is crucial because it determines how we understand Aristotle's psychology and his entire philosophy. If we separate the active intellect from the passive intellect and understand it as God, this indicates that Aristotle's theory of psychology belongs to the theology, not the natural philosophy. Or if natural philosophy and theology are not mutually exclusive, this means that our mental state will be interpreted as two kinds of science, namely, natural philosophy and theology. If active intellect and passive intellect are unified in the individual, then this is a full explanation of human's cognitive activity, maintaining the unity of Aristotle's psychology. As Aristotle himself says in the opening chapter, "It also seems that research into the soul contributes greatly to truth in general, and most especially to truth about nature."

\section{ANALOGY TO KNOWER: INTELLECT AS 'BEING IN POTENTIALITY AND ACTUALITY'}

Just as the Greek word for perception ( $\alpha$ l $\sigma \theta \eta \sigma ı)$ is ambiguous ${ }^{5}$, "it has two meanings, the potential perception and the actuality perception" (DA, 417a14). This distinction also applies to intellect. In the

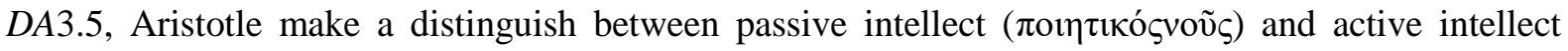
( $\pi \alpha \theta \eta \tau \iota \kappa o ̀ \varsigma v o \tilde{\varsigma})$ in account, according to potential-actuality:

Since [just as] in all of nature there is something which is matter to each kind of thing (and this is what is all those things in potentiality ( $\delta v v \alpha$ ó $\mu \varepsilon$ ) while something else is their cause, i.e. the productive

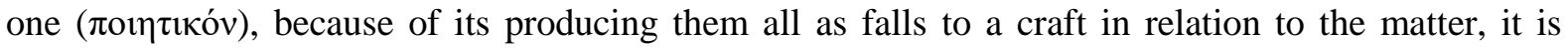
necessary that these differences be present in the soul. And there is one sort of intellect by coming to be ( $\left.\gamma^{\prime} v \varepsilon \sigma \theta \alpha \mathrm{l}\right)$ all things, and another sort by producing ( $\pi \mathrm{ol \varepsilon iv)} \mathrm{them} \mathrm{all,} \mathrm{as} \mathrm{a} \mathrm{kind} \mathrm{of} \mathrm{positive} \mathrm{state,}$ like light. For a certain way, light makes colors which are in potentiality colors in actuality ${ }^{6}$.

The last sentence of this text is the premise of our understanding of passive intellect and active intellect. Active intellect is like light, because in a certain way, light makes colors which are potential to actual colors. There is a debate ${ }^{7}$ about whether active intellect plays a role in the first actualization or in the second actualization. The key to this debate is how to explain potential colors and actual colors.

'being in potential' we cannot say it without qualification and should be distinguished.

\footnotetext{
${ }^{4}$ Fragment 39, Rose, see Miller (2012).

${ }^{5}$ Thomas Aquinas (1999) comments in 416b32-417a2 that the Latin word 'sensus' sometimes refers to perception capacity, but sometimes it also refers to its activity. This ambiguity exists not only in Latin word but

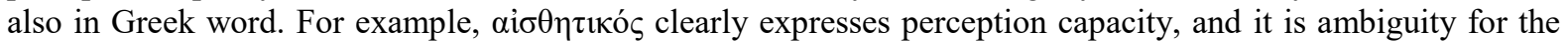
Greek word ai̋ $\sigma \eta \eta \sigma ı \zeta$, which can express both perception capacity and activity. Shields (2016) also expressed this idea. Victor Caston (1996) use aỉo $\theta \eta \tau$ «ós /sensation to represent the form of all kinds of sensations,

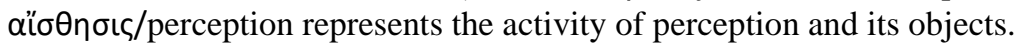

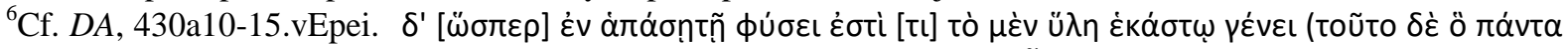

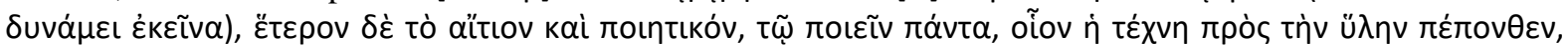

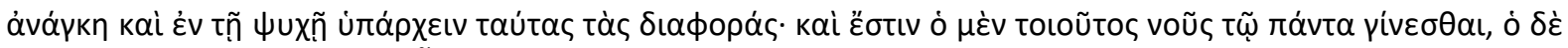

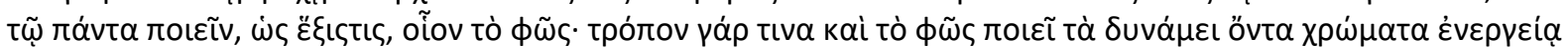

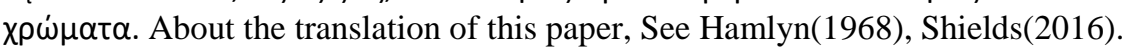

${ }^{7}$ The questions about whether active intellect plays a role in the first actualization or in the second actualization, see Miller (2012). If the light makes the color visible, then this is the first actualization (Aquinas; Kahn); if the color is seeing, it is the second actualization (Kosman; Modrak). In the article, Miller believes that active intellect plays a role in the acquisition and using of knowledge. Based on the understanding of the being of 'potential', this paper insists that active intellect works in the second actualization.
} 
Aristotle said, "In one sense, we say that a child is potentially a general and in the second, we say this someone who is adult ( $D A, 417 \mathrm{~b} 30-31)$. What's the difference between a child here as a 'potential general' and 'potential adult'? The text of Met. will make us clear about this distinction. What's the 'being in potential'? Aristotle tried to give account that "as long as people are willing and there are no external hinders, they will become actuality from potential being. Just as the patient who is being

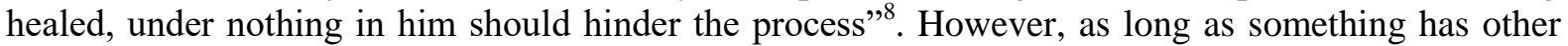
changes before it can begin its own process of actualizing it, then it is not yet being in potential. For example, sperm is not potential human, it must further undergo a change in some other medium, i.e. embryo; the soil is not a potential sculpture, it must change into bronze; the tree is not a potential house, because it needs to be cut and processed. We called something 'being in potential' only when it doesn't add, reduce or change anything. Therefore, the child become general still need to be experienced in the middle, such as learn military knowledge and do military training. Whereas, let us look at the potential in the second sense, the child is the adult in potentiality. As long as there is no accident, he can grow into an adult without having to experience other changes. Just like a person who has knowledge, as long as he wishes to think, can think at any time. So Aristotle said that "when the intellect has becomes $(\gamma \varepsilon \dot{v} \eta \tau \alpha \mathrm{l})^{9}$ each thing in the way that one who actually knows is said to do so (and this happens when he can exercise his capacity by himself), it exist potentially even then in a way, although not in the same way as before it learned or discovered "(DA, 429b5-10). Apparently, the passive intellect as 'being in potential', i.e. the potential in the second sense. Another sort of knower is the one already contemplating, who is in actuality and strictly knowing this $A$. This is the second actualization, i.e. active intellect. Based on this, we make overview of intellect:

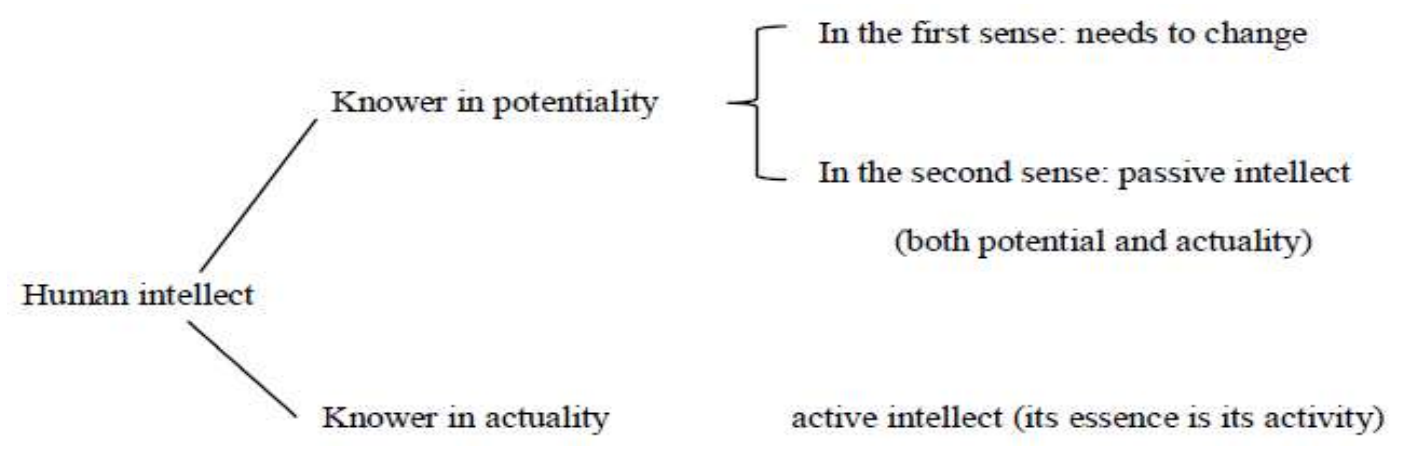

In the analogy, this relationship between potential and actuality is applied to knower who has intellect $^{10}$. A newborn baby, although possessing intellect in the first sense, may become one of many knowers and may become illiterate. It emphasizes a possibility, because contrary exists in the potential. But when he learned, with frequent changes from a contrary state, then we say that he is knower in potentiality in the second sense, which is the passive intellect of human beings. The passive intellect is actuality contrast with potential in the first sense and potential parallel with the active intellect. When we have this potential, we can use it or not, so Aristotle says that "intellect is not always thinking" ( $D A, 430 \mathrm{a} 5)$. Things in potential will not transition to actuality without the efficient cause, so it must correspond to its efficient cause, that is, active intellect. Because of the knower who has intellect can enter into contemplation activities as he wishes. Not only is intellect distinguished between potential and actuality, but also is the object of intellect. The intellectual object in potentiality is the sensible thing in nature, such as stone. The actuality intellectual object is the essence of stone.

So are there two aspects of intellect or two kinds of intellect? Since passive intellect and active intellect are distinguished from its potential and actuality, we begin with the relationship between potential and actuality. Some 'beings' are only actuality, while others are both potential and actuality

\footnotetext{
${ }^{8}$ Met., 1049a6-9, 1049a16-20.

${ }^{9}$ Above the modified verb of passive intellect is $\gamma \varepsilon \dot{\varepsilon} \eta \tau \alpha 1$, the verb prototype of these two Greek words are same. So we deduce that the passive intellect is as the second sense of potentiality.

${ }^{10} \mathrm{We}$ clearly know that 'potential and actuality' is one of most important ways of explaining being in Met. Aristotle does not explicitly give the Greek terms of 'potential intellect' and 'actuality intellect' in the $D A$ text. instead of it, the 'knower being in potentiality' and 'knower being in actuality' are often used by Aristotle. We are not equal the 'knower in potentiality' to passive intellect and 'knower in actuality' to active intellect in the strict sense. But these two are related. It is undeniable that the description of the former can help us understand the unity of the passive intellect and the active intellect.
} 
(Phy., 200b27). So which things are both potential and actuality? Only those things that can be destroyed, changed, not inevitable, neither eternal or permanent, are belong to this, not those that are indestructible, inevitable, and eternal ${ }^{11}$. According to this, human, as perishable being, is exists both potential and actuality. The reason why we called 'being in actuality' just because the 'being the potential' that is relative to it. For example, the finished sculpture is for bronze; the seeing is for have visual but not see; human who thinking now is for knower. So the actuality exists in the things being made, the movement is in the things that are being moved. The activities of building the houses are in the houses being built, and the contemplation activities are in passive reason. Similarly, the material is potentially present, only when it enters into its form and exists in its own form, then it actually exists (Met., 1050a17), and each actuality has its own specific material to make $\mathrm{it}^{12}$. Based on this, it exists one human intellect but have two aspects that is both active principle and passive material, it is like saying that one thing can both have active force and passively effected ${ }^{13}$. When we discuss natural objects or artificial objects, we will distinguish them from its formal and material, but they are identical in subject and cannot be separated. For the same reason, these two aspects of intellect are separable in definition for sake of we discuss it.

\section{THEORETICAL KNOWLEDGE AND WHAT IS KNOWN ARE SAME}

These two aspects of intellect are unified in the individual's thinking act. We still need to examine the activities of passive intellect and active intellect in order to explain deeply the unity of these two aspects. The passive intellect, as a potential, is not like the perception what is born also already has perception, just like we have knowledge. It is an activity that transforms the sensible forms in an image into a form that can be thought through abstraction. Aristotle compares passive intellect to a 'writing tablet' that accepts all essential forms. The active intellect is like the actor who writes the 'word' actuality on the writing tablet, that is, the same between the theoretical knowledge and its object. The passive intellect and active intellect are the same in the thinking activity of the subject.

The activity of passive intellect is the process by which people learn knowledge. In this process, intellect and perception are connected through imagination $(\varphi \alpha v \tau \alpha \sigma i \alpha)^{14}$ and image $(\varphi \alpha ́ v \tau \alpha \sigma \mu \alpha \dot{\alpha})$. Perception capacity can compare all the objects of perception that is present now and discern the difference, but how can we still retain the form of perceptible things after the perceptual activity passes? it depends on imagination and images. Aristotle assumes that imagination is the echo of perceptual activity, and it has the same content as perception. When this perceptual activity is repeated, some images are preserved in the heart, and we have memories of the past. From these images, we can get a logos which is a single experience composed in many memories, a universal concept obtained from many particular things, and the knowledge acquired through induction ${ }^{15}$. Above is just a general description, and it does not specifically describe the role of intellect plays in it. Aristotle believes that intellect is the form of form $(D A, 432 \mathrm{a} 2)$, The meaning of this sentence requires contextual:

Consequently, the soul is a form of form ( $\varepsilon \tilde{i} \delta o \varsigma \varepsilon i \delta \tilde{\delta} v)$, and perception a form of object of perception. Since there is nothing beyond perceptible magnitudes, as it seems, nothing separate, the objects of

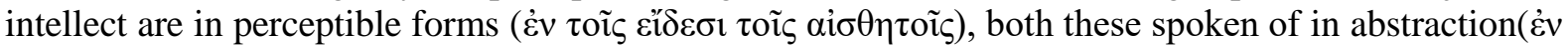
$\dot{\alpha} \varphi \alpha \imath \rho \varepsilon \delta \varepsilon 1)$ and all those which are states and affections belonging to the objects of perception. And because of this, one who did not perceive anything would neither learn nor understand anything, and whenever one contemplates $(\theta \varepsilon \omega \rho \tilde{\eta})$, one necessarily at the same time contemplates a sort of image ( $\varphi \alpha ́ v \tau \alpha \sigma \mu \alpha ́$ ); for images are just as perceptions are, except without matter ${ }^{16}$.

Here eĩ $\delta o \varsigma$ can express two meanings: forms in a broad sense, such as $431 \mathrm{~b} 29$, including forms of perceptible things and the forms of intelligible things; the other is the objects of intellect, which are

${ }^{11}$ Cf.Met., 1050b33-34,1050b16-33

${ }^{12}$ Cf.Met., 1035b5-30, 1033a28-b11; DA,414a28-29.

${ }^{13}$ About this point, I appreciate for Professor Shields.

${ }^{14}$ Plato translates $\varphi \alpha v \tau \alpha \sigma i ́ \alpha$ into belief (Sophist, 264A-B; Theaetetus, 152A-C). Aristotle has similar meanings with Plato, such as things do appear falsely, even among those things concerning which one has at the same time a true perception $(D A, 428 \mathrm{~b} 2)$. But Aristotle's use of the concept of imagination is more of the connection with perception, as the conclusion given by Aristotle that imagination would be a motion effected by actual perception $(D A, 429 \mathrm{a} 2)$.

${ }^{15}$ Cf.Apo. 99b37-100b5; Met., 980b1-981a5.

${ }^{16}$ Cf. DA, 432a1-10. 
the essence of things $(D A, 432 \mathrm{a} 5,429 \mathrm{a} 15,431 \mathrm{~b} 2)$. Perception is what is capable of receiving perceptible forms without the matter, as wax receives the seal of a signet ring without the iron or gold. The material thing (such as stone) is the intellectual object in the sense of the first potential, and our perception capacity can accept the perceptible forms of this stone and other stones. When the perceptional activity repeated, the forms of perceptible things remains in the image. Passive intellect can ignore its characteristics, such as magnitude, size, and then abstract thinkable forms which represent all stones (as the essence of stone).

But the forms that can be thought in images are somehow in potentiality, even though it is not the same way as before learning or discovering. So it needs efficient cause to make itself into actuality, the efficient cause is active intellect. If we do not have this active cause, we cannot think actuality. Analogy to light, there are no actual colors if light is absent. For "being color is the same as being capable of setting in motion what is actually transparent, and the actuality of the transparent is light (DA, 419a10-13). Light makes us to actualize our visual capacity. If there is no other activity besides actuality, then it exists in the subject itself. For example, seeing is in the viewer, and contemplating is in the people who is contemplating now ${ }^{17}$. According to this, active intellect makes us to actualize our passive intellect and writes 'words' actuality on the 'writing tablet'. At this time, 'words' as the thought are as the same as the 'writing tablet', just as the theoretical knowledge is identical to the object of this knowledge. Therefore, active intellect is something that binds thought and the object of thought together, especially concerning about a particular thing.

The efficient cause can be either artificial or natural. The former is that active principle lies beyond the potential, and the latter's active principle is within the potential. If there is no external hinders, the skilled person can actualize something as long as he wishes, then the object is potential through the skill, that is, artificial; If there is nothing external hinders, something can be transfer to actuality through its own active principle and through the natural forces which is located within itself, then the object is potential through nature but artificial. So the active intellect is external or internal principle? First, the activity of active intellect and images cannot be separated, and images is the common attribute of perception, which is belong to perception according to its nature and to intellect accidently ${ }^{18}$. Accordingly, we can infer that active intellect should be a natural force within the person

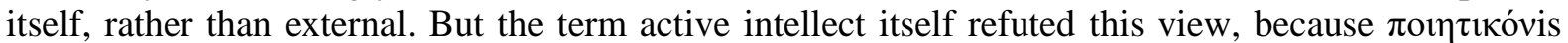
more suitable for the production of artificial objects. The verb of craftsmanship is $\pi$ oisiv, because the production of artificial objects is in the mind of the craftsman. Furthermore, if the active intellect is outside the human, then it is God or first mover emphasized by the divine interpretation.

\section{ACTIVE INTELLECT IS NOT IDENTICAL TO GOD( $\left.\theta \varepsilon \varsigma_{\varsigma}\right)$}

The active intellect as efficient cause in DA3.5 has do some similarities with God. For example, being in essence actuality, as same as its objects, unaffected, eternal and deathless and so on. Therefore, we will not be surprised why some scholars identify active intellect to God or the unmoved mover. But

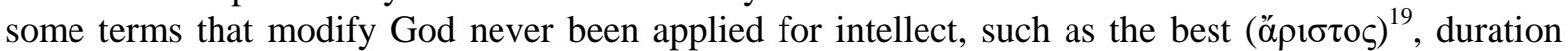
continuous, separate from sensible things $\left(\kappa \varepsilon \chi \omega \rho 1 \sigma \mu \varepsilon \dot{\varepsilon} v \eta^{20} \tau \tilde{\omega} v \alpha i \sigma \theta \eta \tau \tilde{\omega} v\right)$, eternal and actuality

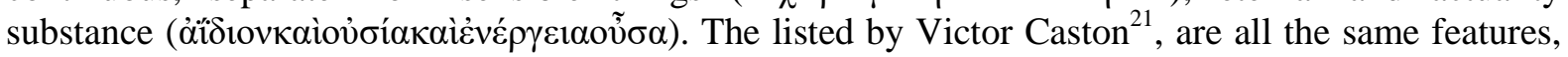
while ignoring different features. It is unfair to identical active intellect in DA3.5 to God.

And having been separated, this alone is just what it is, and this alone is deathless and everlasting, though we do not remember, because this is unaffected, whereas passive intellect is perishable. And without this, nothing thinks.

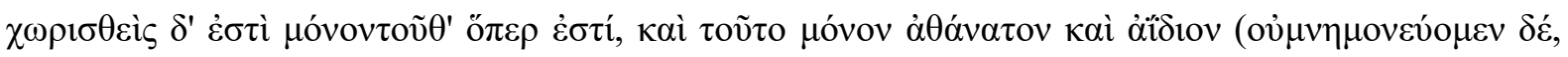

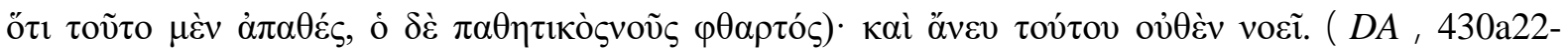

25 )

\footnotetext{
${ }^{17}$ Cf. Met., 1050a35-b1.

${ }^{18}$ Cf.Mem. 450a10-15.

${ }^{19}$ Cf.Met., $1072 \mathrm{~b} 15$.

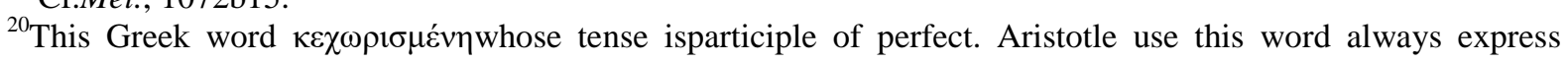
separate in magnitude or place $(G A, 763 \mathrm{~b} 24-25)$. It is a separation completely and unqualified. Whereas, the words modified productive intellect are and $\chi \omega \rho ı \theta$ cì $/ \chi \omega \rho ı \tau$ òv.

${ }^{21}$ See Victor Caston (1999).
} 
- The Greek word ' $\chi \omega \rho ı \theta \varepsilon i \varsigma^{\prime}$ ', which is passive participle of aorist. It indicates entry into a state, or the beginning of a state, and happened in the past time. In other words, it is not always keep this separate state. If it is separated sometimes, this alone is just what it is, i.e. eternal and immortal. The 'separation' here implies conditionality, not always in a state of separation. If it has been in a separate existence, it keeps thinking, and by this time it is already very close to God, actually it is not. The God itself is actuality substance, which is separate ( $\kappa \varepsilon \omega \rho 1 \sigma \mu \varepsilon ́ v \eta)$ in ontological, place, magnitude, unqualified. It has no magnitude and occupy space. The separation of active intellect is occasional and qualified. Therefore, the active intellect here must be the human intellect rather than the first mover in Met.L.

- Although human intellect and God are modified with eternal and deathless, this does not mean that these two are equivalent. Obviously, human intellect can also have divinity and can be shared with eternal in the way that some more some less. áî́ôv (eternal) is wider than $\dot{\alpha} \theta \dot{\alpha} v \alpha \tau$ cov (deathless), $\dot{\alpha} \theta \alpha \dot{\alpha} \alpha \tau o v c a n$ be applied to living things. When Aristotle describes the soul of plant, nutrition capacity, he says, "The nutrition whose functions are generating and making use of food. It is to make another such as itself, an animal an animal and a plant a plant, so that it may, insofar as it is able, partake of everlasting and divine. But these things are incapable of sharing in the everlasting and the divine by existing continuously (because among perishable things nothing can remain the same and the one in number), each has a share insofar as it is able to partake in this, some more and some less" (DA, 415a27-b1). This text explains better about the difference and relationship between human and God. Even the nutrition has divinity through preserve itself, not to mention the human intellect. This idea corresponds to Met. and $N E^{22}$, which also states the happiness which God always enjoys is as great as that we enjoy sometimes, it is marvelous; and if it is greater, this is still more marvelous. The reason why we cannot be continually share in eternal and divine is because we are limited by the body more or less.

- The active intellect and human memory. Why do we forget things, even though we have active intellect. The question Aristotle to answer is that active intellect is unaffected. Whereas, memory relies on the function of body organ ${ }^{23}$. This also proves that active intellect belongs to human being, because Aristotle tries to solve the question why we don't remember. After the separation of active intellect, we assuredly have no previous experience and memory. For these experiences and memories are possessed by passive intellect that disappears with the body. Therefore, passive intellect is perishable. But without active intellect, we can't think actuality, it is the active principle for our thinking.

In summary, human intellect as a part of soul, is the part of our the closest to God and the farthest part from the body. According to potential and actuality, the intellect has distinguished between passive intellect and active intellect. The active intellect is more represent for the essence of human intellect. For what acts is always superior to what is affected, as too the first principle is to the matter whether in account or substance ${ }^{24}$. Analogy to knower, who is being in potentiality when he has been knowledge and being in actuality when he is contemplating. There is only one intellect just like one knower. Passive intellect is like 'the material of thought', active intellect is the form of 'thought'. The activity of passive intellect, i.e. our process of learning knowledge, we can't call it thought. Only when passive intellect enters into contemplation is it the essence of intellect. Similarly, if there is no passive intellect as the material of 'thoughts', active intellect can't actualize what it is. No matter what you think, or think about something, or think about yourself, there must be something that prior to it and transfer it to actuality, so Aristotle sets the active intellect in metaphysical sense. It involves turning thinkable forms in image into thinking actuality, just like the contemplation knowledge is identical to the object of knowledge. The active intellect plays important role in our thinking act. Based on above, the active intellect is not identical to God, because their separate state is different. This interpretation will further maintain the consistence of Aristotle's entire philosophy. On the contrary, if the active intellect, as held the divine interpretation, is a kind of non-personal existence that exists outside human soul, then such interpretation will inevitably make us understand Aristotle as a Platonism, or an individualism, Immortal Christians, which is far from Aristotle true intention.

\footnotetext{
${ }^{22}$ Cf. Met.1072b25;NE, 1177b33.

${ }^{23}$ Cf.Mem., 449b18-22.

${ }^{24}$ Cf.DA, 430a19; Met., 1049b11.
} 


\section{REFERENCES}

[1] Alexander of Aphrodisias. Alexander of Aphrodisias: On the soul, translated with an introduction and commentary by Victor Caston. London: Bloombury, 2012.

[2] Bywater. Aristotle Ethica Nicomachea. Oxford: Oxford University Press, 1984.

[3] Broadie. Nousand NatureinDe AnimaIII. Proceedings of Boston Area Colloquium in Ancient Philosophy 12, 163-92.

[4] Christopher Shields. Aristotle: De Anima. Oxford: Clarendon Press, 2016.

[5] Caleb. Nous in Aristotle's De Anima. Philosophy Compass9/9(2014):594-604.

[6] Deborah K. W. Modrak. The Nous-Body Problem in Aristotle. The Review of Metaphysics, Vol.44, No.4 (1991).

[7] Frede Michael. On Aristotle's Conception of Soul. Essays on Aristotle's De Anima,Eds.Martha C. Nussbaum, Amelie Oksenberg Rorty.Oxford: Clarendon Press, 1995.

[8] F. Granger. Aristotle's Theory of Reason. Mind, New Series, Vol.2, No.7(1893).

[9] Fred D. Miller, JR. Aristotle on the Separability of mind. The Oxford of Handbook of Aristotle, edited by Christopher Shields. New York: Oxford University of Press, 2012.

[10] Hamlyn.D.W. Araistotle De Anima. Oxford: Oxford University Press, 1968.

[11] Gail Fine. Separation. Oxford Studies in Ancient Philosophy 2:31-87 (1984).

[12] Kahn, C.H. Aristotle on Thinking, in Essays on Aristotle's De Anima, Edited by M.C.Nussbaum and A. Rorty. Oxford: Clarendon Press: 359-79,1995.

[13] Lloyd P. Gerson. The Unity of intellect in Aristotle's De anima. Phronesis Vol.49, No.4 (2004). Myles F. Burnyeat. Aristotle's Divine Intellect. Milwaukee: Marquette University Press, 2008.

[14] Michael V. Wedin. Mind and Imagination in Aristotle. New Haven, London: Yale University Press, 1988.

[15] Philip J. Van Der Eijk. Aristotle's Psycho-physiological Account of the Soul-Body Relationship. Psyche and Soma, edited by John P. Wright and Paul Potter. Oxford: Clarendon Press, 2000.

[16] R.D. Hicks. Aristotle De Anima with Translation, Introduction and Notes. Cambridge : Cambridge University Press, 1907.

[17] Thomas Aquinas, translated by Robert Pasnau.A Commentary on Aristotle's De Anima.Yale: Yale University Press, 1999.

[18] Thimistius. On Aristotle's on the soul, translated by R. B. Todd. London, Ithaca. NY: Duckworth and Cornell University Press, 1966.

[19] Thomas M. Robinson. Aristotle, the intellect and cognition. Frontiers of Philosophy in China, Vol.9, No2 (June 2014).

[20] Victor Caston. Aristotle's two Intellect: A Modest Proposal. Phronesis 44(1999):199-227.

[21] Victor Caston. Why Aristotle needs imagination. Phronesis 41(1996):20-55.

[22] W.D. Ross. Aristotle De Anima. Oxford: Oxford University Press, 1956.

[23] W. Jaeger. Aristotle Metaphysics. Oxford: Oxford University Press, 1957.

[24] W.D. Ross. Aristotle's Metaphysics. A Revised Text with Introduction and Commentary. Oxford: Oxford University Press, 1924.

\section{AUTHOR' BIOGRAPHY}

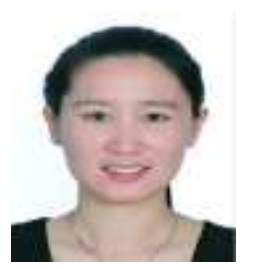

Hua Wang, is a Ph.D. student at Beijing Normal University in the School of Philosophy now. I studied as a visiting scholar at University of Notre Dame in 2017.8-2018.8. And I got a master's in philosophy from Soochow University in 2015. My research fields include Ancient Greek Philosophy, Aristotle's ethics and nous-body problem.

Citation: Hua Wang. "The Unity of Intellect in Aristotle's De Anima". International Journal of Humanities Social Sciences and Education (IJHSSE), vol. 6, no.11, 2019, pp. 44-50. doi: http://dx.doi.org/10.20431/2349. 0381.0611007.

Copyright: (c) 2019 Authors. This is an open-access article distributed under the terms of the Creative Commons Attribution License, which permits unrestricted use, distribution, and reproduction in any medium, provided the original author and source are credited. 